\title{
The Use of User Centered Design Method for designing Virtual Laboratory based on Virtual Reality (Turning Machine Case Study)
}

\author{
$1^{\text {st }}$ Singgih Saptadi ${ }^{1}, 2^{\text {nd }}$ Deny Nurkertamanda ${ }^{2}, 3^{\text {rd }}$ Yusuf Widharto $^{3}, 4^{\text {th }}$ Anna Nur Maliansari $^{4}$ \\ $\underline{\text { singgihs@ft.undip.ac.id }}{ }^{1}, \underline{\text { nurkerta@gmail.com }}^{2}$, yudidito@gmail.com ${ }^{3}, \underline{\text { amaliansari@gmail.com }}^{4}$
}

\author{
${ }^{1,2,3,4}$ Department of Industrial Engineering, Faculty of Engineering \\ Diponegoro University, Semarang, Indonesia
}

\begin{abstract}
Referring to accident data at the Production System Laboratory (PSL) indicating that most of the accident in the practice of manufacturing process occurs when operating the turning machine. These accident happened as a result of cumulative obstacles that faced by students when operating turning machine. This obstacles start from insufficient time for training that was followed before practice of manufacturing process in laboratory, to give student an experience before practice of manufacturing process. To help student encountered with their obstacles this research offered the use of virtual reality as a learning process for turning machine before they use the real machine. The user centered design (UCD) method used in designing applications especially phase 1 to 3.
\end{abstract}

Keyword: Turning Machine, manufacturing process, virtual reality

\section{Introduction}

Industrial Engineering Department as a part of Faculty of Engineering in Diponegoro University has already implemented technology in most of its learning activities [1]. Industrial Engineering try to become one of the major that make manufacturing process as it main subject. To achieve that goal practice of manufacturing process which carried out to implement technique of production using the real machinery was given to student at third semester. This practice took place at the Production System Laboratory (PSL), curriculum of the practices demand student to attend machining training before practices, namely lathe and milling machines. The accident data at the PSL shows that most practical errors occur when operating a turning machine.

These errors came as a result from cumulative factor. One of the factor is the lack of machine training, The other factor that contribute were limited number of machines and machine breakdown. When practices outside the laboratory student also faced by problem that the machine model is different from the machine that use in the laboratory also if the student trained outside the laboratory they have to buy their own materials for machinary training and travel long distances to get to the training center [6]. This research come as a way to help student with their problem by designing media in the form of applications, namely virtual laboratory application [11-12] based on virtual reality that try to make virtual turning machine in PSL that can be used to prepared student before entering the manufacturing process practice. This application is done using the user centered design (UCD) method [4, 7, 8]. The benefit that can get form the use of virtual laboratory one of them is can be a learning media to simulate experimental activities in the laboratory [15]. The other were costless, more safety, and has a great of flexibility in the field of a visual learning style [13]. Based on the previous 
research done by Saleh, it proves that the virtual laboratory is very useful as a media for safe and inexpensive teaching [14].

For the virtual laboratory applications, some operations are chosen because they are basic operations performed in the manufacturing process practicum annually. In making this application, 3D object modelling is created using Blender [9], while app design is created using Unity $3 \mathrm{D}[2,3,9]$.

\section{Research Design}

This research uses user centered design (UCD) method in designing virtual laboratory applications. UCD method is a way that involve of user interface design with goals on usability, character, environment of user, process work, and flow when design on an interface [5]. In this paper wil demonstrate three step out of four that happened during design process UCD method, there are principles that must be considered in the 4 phase method $[4,8,10]$.

\section{Phase 1. Specify the Context of Use}

In this phase, the stakeholders/actors identification is carried out by interviewing the parties that responsible to the level management of the PSL. Stakeholders in this case are the interested parties in the implementation of the manufacturing process practicum, which is the lecturer and, the PSL'S assistant. While actors are the users who run the application, which are students (the practicum participants). Furthermore, the development of virtual laboratory concept in accordance with the learning must be mastered by the students before the implementation of the manufacturing process practicum.

Table 1. Role and Duties of Stakeholders / Actors

\begin{tabular}{llll}
\hline No. & Stakeholder/Actor & Role & Duties \\
\hline 1 & Lecturer & Organizer & Make the curicullum \\
\hline 2 & Assistant at Laboratory & Organizer & $\begin{array}{l}\text { Help, supervise and } \\
\text { controlling the practices. }\end{array}$ \\
\hline 3 & Student & Participant & $\begin{array}{l}\text { Attending and following } \\
\text { instruction during practice }\end{array}$
\end{tabular}

Turning machine applications in this research will be developed into a virtual laboratory, because it is cheaper, safer, and flexible for use by student. The use of a virtual laboratory application can simulate the activities carried out at Industrial Engineering Production Laboratory (LSP) as a learning facility for practicum preparation for the manufacturing process.

In learning of turning machine, this virtual laboratory application will develop the subject matter and work process in the names of turning machine parts and the steps to operate the turning machine was carried out. This virtual laboratory application was developed only to the operation of the turning machine, because it is used in the context of learning for laboratory. 


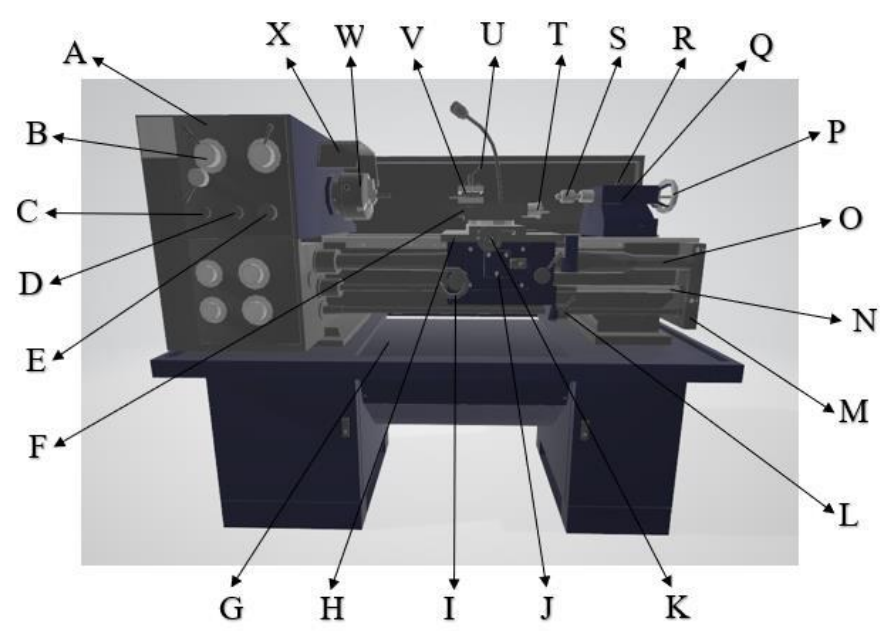

Fig. 1. Turning Machine Part at Laboratory

Table 2. Part Name of Turning Machine

\begin{tabular}{cl}
\hline Figure & \\
\hline A & Headstock \\
\hline B & Spindle Speed Selector \\
\hline C & Indicator Lamp \\
\hline D & Jog Button \\
\hline E & Emergency Button \\
\hline F & Compound Rest \\
\hline G & Chip Bin \\
\hline H & Saddle \\
\hline $\mathrm{I}$ & Feed Wheel (Bottom X Axis) \\
\hline J & Apron \\
\hline $\mathrm{K}$ & Feed Wheel (Y Axis) \\
\hline $\mathrm{L}$ & Start, Stop, and Reverse Lever \\
\hline $\mathrm{M}$ & Bed \\
\hline $\mathrm{N}$ & Feed Rod \\
\hline $\mathrm{O}$ & Lead Screw \\
\hline $\mathrm{P}$ & Tailstock Handwheel \\
\hline $\mathrm{Q}$ & Tailstock \\
\hline $\mathrm{R}$ & Tailstock Lock \\
\hline $\mathrm{S}$ & Center \\
\hline $\mathrm{T}$ & Feed Wheel (Upper X Axis) \\
\hline $\mathrm{U}$ & Toolpost Lock \\
\hline $\mathrm{V}$ & Toolpost \\
\hline $\mathrm{W}$ & Chuck \\
\hline $\mathrm{X}$ & Chuck Protector \\
\hline
\end{tabular}

In learning the operation of this turning machine process, only 3 turning machine operations were carried out, namely leveling the surface (facing), reducing the diameter (diameter reduction), and cutting off part (cut off). 


\section{Phase 2. Specify User and Organizational Requirements}

In this phase, the use case diagram is formed based on the result data from turning machine work.. The results of the use case diagram are used to identify the requirements of students as well as the limitations on the development of practicum learning requirements. This requirements are divided into two, namely functional requirements and non functional requirements.

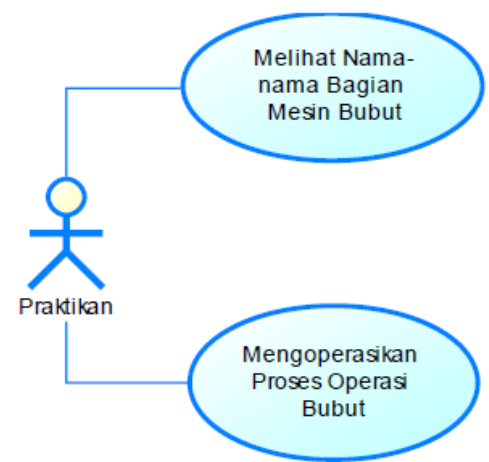

Fig. 2. Use Case Diagram Learning of Turning Machine

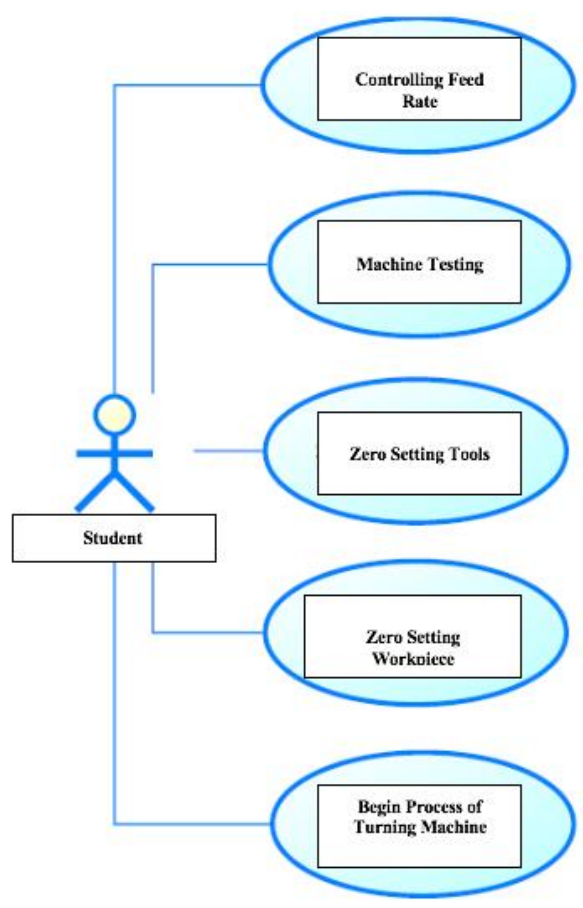

Fig. 3. Use Case Diagram Learning Operating Turning Machine 
Based on the development of the concept of virtual laboratories and the limitations that have been explained in the use case diagram of practical learning, functional requirements in this virtual laboratory application can be determined, namely:

1. The application provides information in the form of an explanation of the name and function of work equipment in the Industrial Engineering Laboratory (LSP).

2. The application provides information in the form of an explanation of the names of turning machine parts.

3. The application provides information in the form of an explanation of the steps for setting the zero tool and setting the zero workpiece.

4. The application interacts with the user to operate the test machine.

5. The application interacts with the user to carry out 3 lathe operations processes, namely the process of leveling the surface (facing), reducing the diameter (diameter reduction), and cutting some objects (cut off).

Non-functional needs describe things that are more critical than functional needs. Nonfunctional requirements in the development of virtual laboratory applications are determined in 2 parameters, namely reliable (usability) and usability. Non-functional requirements on each parameter are based on predetermined functional requirements, then be explained in more detail about the limits or quality expected from this turning machine learning application.

\section{Phase 3. Design Solution}

In this phase, the application design is carried out based on the result of the data from phase 2 of functional requirements and non functional requirements. The application design stages start from 3D object modeling, automatic animation creation, interface designing, layout 3D positioning and object placement, sound processing, and animation processing. LSP.VR has 3 menus on the main menu, namely the LSP introduction menu, the lathe process menu, and the menu quit. In the LSP Introduction menu, users can explore the room while interacting with work equipment and lathes to find out the name and function of the equipment. In the lathe process menu, users can interact with lathes using 6 sub menu, namely machine test, facing, diameter reduction, cut off, workpiece setting, and chisel setting.

3D object modeling is done using Blender software, which consists of a meshing and texturing process to produce 3D objects in the form of work tools, lathes, and architecture buildings of the Production System Laboratory (LSP). 


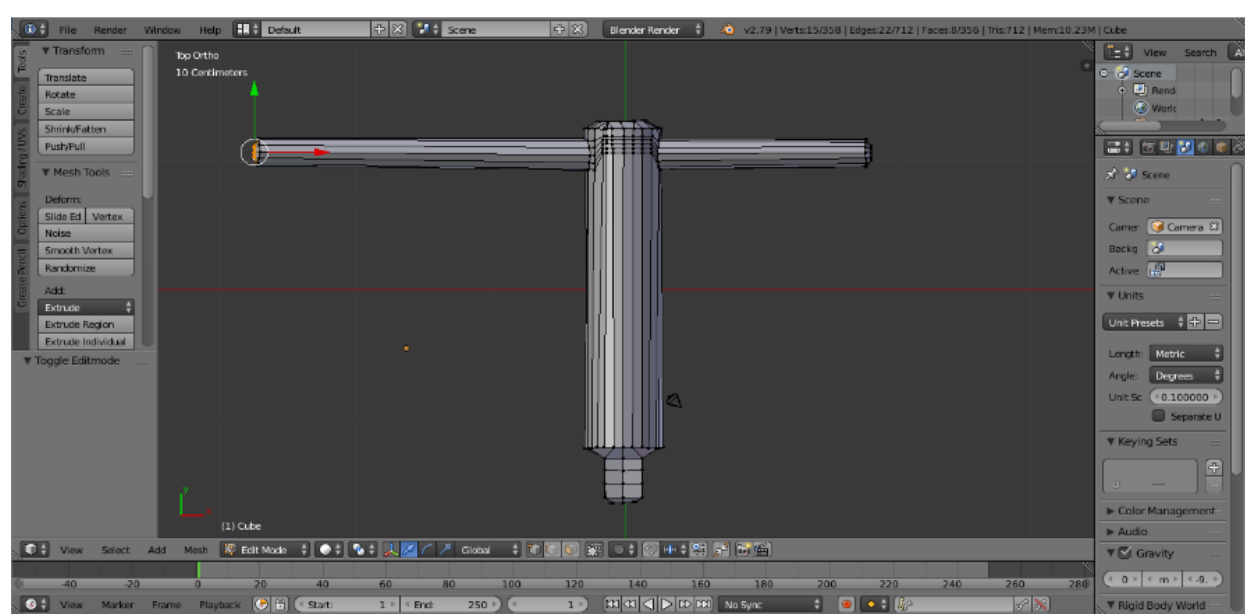

Fig. 4. Meshing Process of Chuck Key

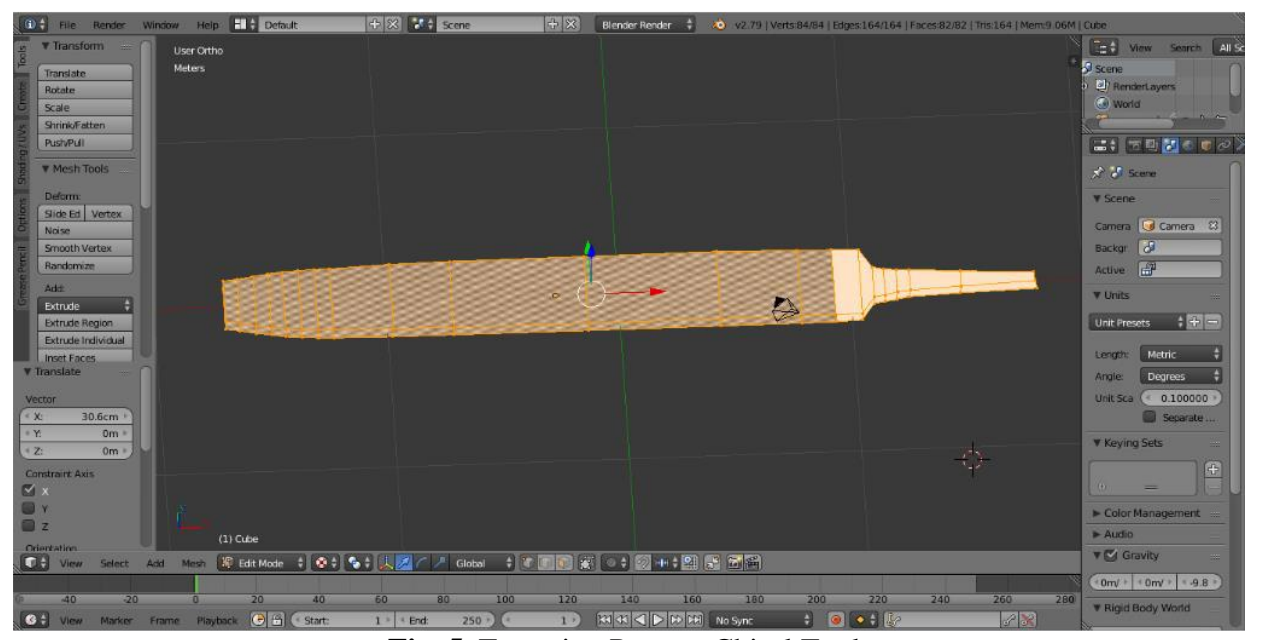

Fig. 5. Texturing Process Chisel Tools

Animation process is done using Blender software. This animation is processed to design an automatic motion / animation simultaneously when a function is run. Animation made consists of toolpost movements and compound rest in the lathe operation process (facing, diameter reduction, cut off), and the movement of falling leftovers 


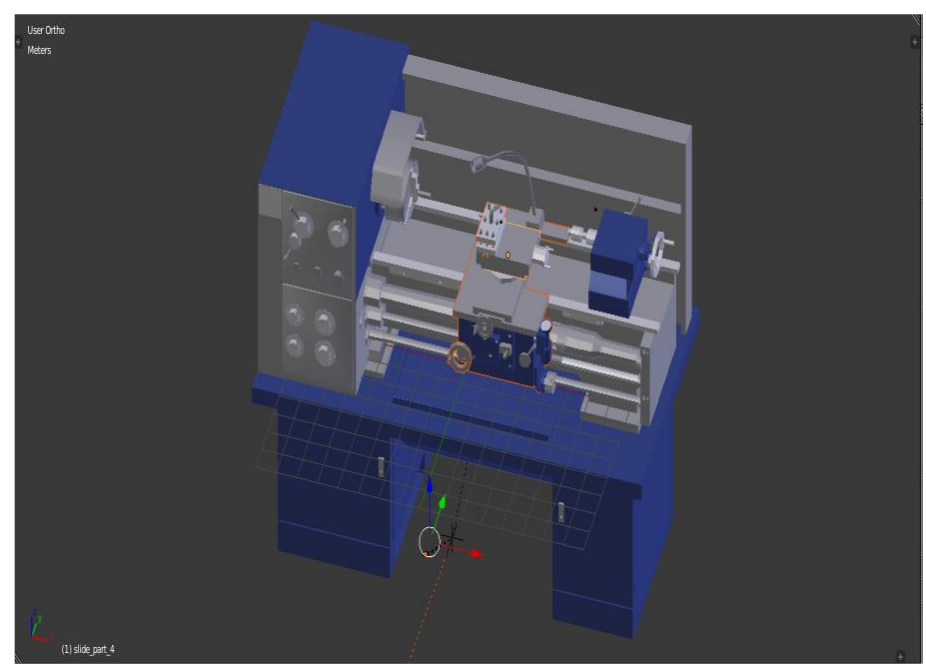

Fig. 6. Animation of Turning Machine

\section{Conclusion}

This research uses UCD method for application development, where there are four phases and this research demonstrate 3 out of 4 phase that must be done, namely specify the context of use, specify user and organizational requirements, design solutions, and evaluate design against user requirement. In specify the context of use phase, interviews are conducted to identify related stakeholders. In specify user and organizational requirements phase, use case diagram modelling is based on the result of phase 1 to identify functional requirements and non-functional requirements in practical learning. In design solutions phase, the application design is done using Blender and Unity 3D software based on the requirements obtained from phase 2 .

\section{References}

[1] Astuti, Windi. (2009). Building of Industrial Engineering Study Program and Student Facilities Faculty of Engineering UNDIP in Semarang with energy efficient building concept. S1 Thesis, Diponegoro University

[2] Creighton, R. (2010). Unity 3D Game Development by Example Begginer's Guide. Packt Publishing Ltd.32 Lincoln Road 32 : Birmingham, B27 6PA, UK

[3] Dani, Faiq S. (2017). Design Build 3D Virtual Map of Lampung University Computer Science Department using Unity 3D. Thesis. Unpublished. Faculty of Mathematics and Natural Sciences, University of Lampung: Bandar Lampung

[4] Fathoni, Rizky. (2010). Designing Interface Website E-commerce Griya Batik and Embroidery Prima Lestari with User Centered Design Method ISO 13407. Bachelor's End Job, Diponegoro University

[5] Jeffrey Rubin. (1984). Handbook of Usability Testing: How to Plan, Design, and Conduct Effective Tests. John Wiley and Sons, Inc

[6] Napitupulu Junita, Pangaribuan, Atur, dan Turnip, Togu. (2010). Modelling of the Virtual Laboratory Science, the Final task Diploma III Information Engineering Course of Informatic Polytechnic

[7] Priandrani, Aldis. (2011). Designing design in PC Mini Games Using User centered design Method (Case Study in Industrial Engineering UNDIP's Students). Bachelor's Degree, Diponegoro University 
[8] Sinaga, Eliakim. (2012). Redesign of the Design Interface of Human Error Investigation Application in Train Accident Using User Centered Design Method. Bachelor's Degree, Diponegoro University

[9] Vidiardi, Servasius. (2015). The Development of the Interactive Virtual Museum Uses Virtual Reality Desktop Technology in the Ranggawarsita Museum. S1 Thesis, State University of Semarang

[10] Widhiarso, Wijang, Jessianti, and Sutini. (2007). User Centered Design Method for Information Kiosk Design, Case Study: The XYZ Maternity Hospital. 3(3)

[11] Dobrzanski LA \& Honysz R. (2010). The idea of material science virtual laboratory. Journal of Achievements in Materials and Manufacturing Engineering vol. 42 (1-2):196203 On Line at http://jamme.acmsse.h2.pl

[12] Domingues L, Rocha I, Dourado F, Alves M \& Ferreira EC. (2010). Virtual laboratorios in (bio) chemical engineering education. Journal Education for Chemical Engineers vol. 5: e22-e27 On Line at www.elsevier.com

[13] Jian, Brown DJ \& Billet E. (2005). Development af a virtual laboratory experiment for biology. European Journal of Open, Distance and E-learning vol. 1 (195): 1-8 On Line at http://www.eurodl.org.

[14] Saleh KF, Mohamed AM \& Madkour H. (2009). Developing virtual laboratory environment for engine education. International Journal of Arts and Sciences vol. 3 (1):917. On Line at openaccesslibrary.org

[15] Trimannula, Ajib. (2017). Virtual Tour Based on 3D for the Introduction of STIKI Campus, Malang. Journal of Information and Technology, vol 5 (1), jurnal.stiki.ac.id/JINTECH 